The UK - government, citizens and the profession - must modernise its thinking about dentistry, and end the attitude that pigeonholes dentistry and excludes it from the rest of health care

\title{
These changing times
}

I n the week that Bob Dylan turned 60, the Labour Party election strategists finally turned to the issues that they believed would secure them the much-prized second term. Vote, we were urged, for schools and hospitals. Public services had become the election issue, but Labour's strategists knew there were risks. In 1997, Labour was elected on the promise of sorting out education and the NHS. Concentrate only on public services, and an opposition with a coherent approach to the public sector might have been able to inflict serious damage.

With the second term now secure, can we hope for better for our health service? One of the Prime Minister's most significant decisions in forming his new Cabinet was to keep Alan Milburn at the Department of Health. Health is often a cabinet graveyard post (in recent times, only Ken Clarke has moved on to greater office). Mr Milburn may have wanted to move, but he has two advantages on his predecessors. He is still seen as a rising star in the Labour Party, generally performing well in a difficult brief, and he has the sort of money for investment in the new NHS that others have only dreamed of. Tony Blair knows that the NHS could still cause the Labour Government's downfall. Alan Milburn has a lot to deliver for the Government, and he knows that the next 18 months are critical, not just for his own political future.

So where does this leave dentistry? The BDA has argued that the Government cannot fulfil their pledge to deliver the modernised NHS, fit for the 21st century, without taking seriously the major problems in NHS dentistry. These arguments were delivered undiluted to the Government by the House of Common's Health Committee in its March report on access to NHS dentistry. The BDA's pre-election discussions suggest that Ministers are willing to look in depth at the problems. While the BDA was careful not to seek a pre-election agreement that could simply be ignored in a new mandate, it does expect the Government to consider solutions that do more than previous governments have ventured in this important area of health care.

So will the Government be true to its pre-election promises? The profession has bitter memories of post-election betrayal, but there may be grounds for believing there will now be serious discussions. Lord Hunt, the outgoing minister for dentistry, has laid a good foundation, but his path has not been smooth, and the disappointing 'Modernising NHS Dentistry' shows that there are still powerful interests to engage and convince.

Hazel Blears, the new minister, takes over a full dental brief, and great expectations from the profession. Yet the future of NHS dentistry will be discussed against a backdrop of changing times. Milburn's surprise announcement of a radical shake-up in NHS management, just days before the election was called, has put the health service in England into a frenzy of change that will have profound implications. Somehow, among the upheavals, a revitalised and modernised NHS has to emerge.

For dentistry, though, there is another change, more profound than any of those mentioned. The UK - government, citizens and the profession - must modernise its thinking about dentistry, and end the attitude that pigeon-holes dentistry and excludes it from the rest of health care.

The dental profession is a huge resource of highly-qualified clinicians who have a full part to play in the organic system of UK health care. It is time that it was recognised as such.

So, together with changes in the system by which dentistry and oral health Ian Wylie Chief Executive, BDA care is delivered, dentistry must be shown to be a full part of the modern health economy. That would indeed be change. 